1 Instituto de Pesquisa Econômica Aplicada (Ipea) - Brasília (DF), Brasil. luciana.servo@gmail.com

2 Fundação Oswaldo Cruz (Fiocruz) - Rio de Janeiro (RJ), Brasil.

\section{Financiamento do SUS e Covid-19: histórico, participações federativas e respostas à pandemia}

\author{
SUS financing and Covid-19: history, federative participation, and \\ responses to the pandemic
}

Luciana Mendes Santos Servo', Maria Angelica Borges dos Santos'2, Fabiola Sulpino Vieira1, Rodrigo Pucci de Sá e Benevides ${ }^{1}$

DOI: 10.1590/0103-11042020E407

RESUMO Este ensaio discute o financiamento do Sistema Único de Saúde (SUS) em perspectiva histórica e futura, considerando os desafios sanitários e econômicos impostos pela pandemia de Covid-19. Como sempre e mais do que nunca, precisa-se discuti-lo. Essa necessidade cresce em premência a partir da recessão econômica que o País viveu em 2015 e 2016, pela estagnação da economia nos anos seguintes e pela recessão que já surge no segundo trimestre de 2020 com previsão de aprofundar-se nos próximos anos. A pandemia acontece em um contexto de redução da participação federal no financiamento, pouco espaço para estados ampliarem suas fontes de financiamento e problemas de coordenação entre os entes federativos. No caso do financiamento das Ações e Serviços Públicos de Saúde (ASPS) para enfrentamento da pandemia, argumenta-se neste texto que ele passa necessariamente pela ampliação dos recursos alocados ao SUS, com grande dependência da atuação do governo federal. Contudo, nem com a urgência que demanda a pandemia houve rapidez na liberação e execução dos novos recursos aprovados pelo Congresso Nacional. Conclui-se que as perspectivas não apontam para uma priorização do SUS nem para ampliação do seu financiamento no período pós-pandêmico.

PALAVRAS-CHAVE Financiamento da assistência à saúde. Federalismo. Serviços de saúde. Pandemias. Coronavírus.

ABSTRACT This essay discusses financial resources for Brazil's Unified Health System (SUS) in a historical and future perspective, considering the health and economic challenges imposed by the Covid-19 pandemic. As always and more than ever, we need to discuss the SUS financing. This is aggravated in intensity by the context of the chronic economic recession which the country experienced in 2015 and 2016, followed by stagnation in the following years and accentuated in urgency by the recession in the second quarter of 2020 and that is expected to deepen in the comingyears. The pandemic happens in a context of diminishing federal participation in the SUS financing, little space for states to expand their sources of financing, and several problems of coordination between federal entities. We argue that facing the pandemic necessarily involves an expansion of resources for financing the SUS and it has a great dependence on the performance of the federal government. However, even with the urgency that the pandemic demanded, the new resources approved by the National Congress for the public health system has been quite slow. We conclude that the prospects do not point to prioritizing the SUS and expanding its funding in the post-pandemic period.

KEYWORDS Healthcare financing. Federalism. Health services. Pandemics. Coronavirus. 


\section{Introdução}

O ano de 2020 ainda não terminou, mas sua marca na história mundial já é inegável. No final de 2019, o surgimento de um caso de um novo coronavírus letal em uma província chinesa não permitiria antever que três meses depois a doença já teria se espalhado pelo mundo. Ainda hoje, discute-se quando a doença teria chegado ao Brasil11. O primeiro paciente foi oficialmente confirmado em 26 de fevereiro de 2020, vindo da Itália. Em 21 de junho de 2020, já eram mais de 1 milhão de casos oficialmente confirmados e 50,6 mil óbitos ${ }^{2}$, com o País ocupando o triste segundo lugar nas estatísticas de mortalidade mundiais, atrás apenas dos Estados Unidos ${ }^{3}$.

A crise sanitária que vive o Brasil se agravou com as divergências entre o governo federal e os entes subnacionais sobre as medidas de prevenção, controle e tratamento dos casos relacionados com a pandemia. No centro desse debate, estava um falso dilema entre economia e saúde ${ }^{4,5}$, chegando-se a afirmar que, se o País adotasse medidas de isolamento, a crise econômica seria mais prejudicial que a crise sanitária.

No mundo, esse dilema parecia ter sido desfeito por estudos que demonstraram a importância da adoção de medidas econômicas nacionais rápidas, para proteger empresas e garantir renda mínima aos cidadãos, associadas a diferentes medidas de isolamento, ampliação da testagem e da capacidade de resposta do sistema de saúde para enfrentamento das crises geradas pela pandemia ${ }^{6-8}$.

No Brasil, intenso debate acontecia enquanto os casos se multiplicavam. Os estados e os municípios divergiram do governo federa ${ }^{5} \mathrm{e}$ foram adotando medidas locais diferenciadas ${ }^{9}$. Medidas nacionais, como garantia de renda mínima e de emprego, além do apoio às empresas, começaram a ser tomadas no começo de abril e implementadas no final daquele mês, quase dois meses após o primeiro caso ser confirmado. No que diz respeito às questões estritamente relacionadas com o sistema de saúde, a pandemia revelou a necessidade urgente de novos recursos e de ampliação de investimentos para reduzir as desigualdades de acesso entre grupos populacionais e entre regiões do País ${ }^{10-13}$.

Se o financiamento adequado é uma necessidade do sistema de saúde ${ }^{14}$, essa questão torna-se premente em um momento de crise sanitária gerada pela pandemia. No caso brasileiro, o financiamento da saúde é assumido de forma desigual pelos governos e pela sociedade. Como proporção do Produto Interno Bruto (PIB), os gastos do Brasil em saúde foram de $8,0 \%$ em 2010 e $9,2 \%$ em $2017^{15}$, com suaves oscilações entre os anos. Em 2011, foi de 7,8\% do PIB, ao passo que, no ano de 2016, registrou-se as maiores despesas em saúde como percentual do PIB, de 9,3\%, menos relativa a aumento de gasto e mais à recessão econômica que reduz o PIB e afeta o indicador.

Ainda que as salvaguardas instaladas com a Constituição Federal de 1988 (CF/88) ${ }^{\mathbf{1 6}}$, a Emenda Constitucional no 29 de 2000 (EC 29) ${ }^{17}$ e legislações subsequentes ${ }^{18}$ tenham assegurado aumento dos gastos públicos em saúde como proporção do PIB nos últimos 20 anos, no período 2010 a 2017, o incremento nos gastos públicos foi menor do que o privado, com uma participação mínima de 3,4\% do PIB em 2012 e a máxima de 4,0\% do PIB em 2016. Anos com proporções mais altas coincidem com períodos de crise econômica, indicando os efeitos do encolhimento relativo do PIB, que infla a participação dos gastos em saúde ${ }^{\mathbf{1 5}}$.

Como sempre e mais do que nunca, precisamos discutir o financiamento do Sistema Único de Saúde (SUS). Essa necessidade intensificou-se a partir da recessão econômica que o País viveu em 2015 e 2016, pela estagnação da economia nos anos seguintes, pela recessão que já surge no segundo trimestre de 2020 e pela previsão de profunda recessão no pós-Covid. No caso do financiamento das ações e serviços públicos de saúde para enfrentamento da pandemia, argumentamos neste texto que ele passa necessariamente pela ampliação da alocação de recursos ao SUS, com grande dependência da atuação do 
governo federal. Isso se deve ao fato de que: 1) há atribuições da política econômica que são exclusivas do governo federal; 2) a maior parte da arrecadação tributária está concentrada na União; 3) o SUS já estava subfinanciado há anos, apesar da ampliação da participação de estados e, principalmente, de municípios desde os anos 2000; 4) o subfinanciamento foi agravado por medidas de limitação do gasto público adotadas pelo governo federal.

Considerando esse contexto, o presente ensaio tem por objetivo discutir o financiamento do SUS em perspectiva histórica e futura, considerando os desafios sanitários e econômicos impostos pela pandemia de Covid19. A próxima seção resgata os marcos legais do financiamento do SUS e o histórico de insuficiência de recursos do sistema ao longo de toda a sua existência. A terceira seção examina como os entes federativos têm assumido responsabilidades distintas pelas várias funções de atenção e quais as implicações disso na atual situação da pandemia. A quarta seção discute a alocação de recursos federais para saúde em resposta à emergência de saúde pública gerada pela pandemia. E, por fim, são apresentadas as considerações finais.

\section{Financiamento do SUS: trajetória de alocação insuficiente de recursos e de luta}

O SUS é marcado por uma trajetória de luta em torno de seu financiamento ao longo desses quase 32 anos desde a criação do sistema pela $\mathrm{CF} / 88$. Ainda que os constituintes tivessem se preocupado em determinar a participação das três esferas de governo no seu financiamento e previsto fontes de receitas e alocação de recursos mínimos pela União, nos primeiros anos do SUS e durante os anos 1990, o mandamento constitucional foi totalmente ignorado.

No âmbito da União, havia a determinação de que $30 \%$ do Orçamento da Seguridade
Social (OSS), excluído o seguro-desemprego, fossem alocados ao SUS até que a lei de diretrizes orçamentárias fosse aprovada. A regra não foi cumprida, tendo sido finalmente vetada em $1994^{19}$. A falta de recursos para financiamento dos serviços deflagrou crise importante no SUS e obrigou o Ministério da Saúde (MS) a recorrer a empréstimos no Fundo de Amparo ao Trabalhador 20.

Além do descumprimento da regra transitória de aplicação de recursos no SUS pelo governo federal, da falta de vontade política para garantir recursos em montante suficiente para evitar a crise de financiamento do sistema e de o Congresso não aprovar novo dispositivo constitucional obrigando a aplicação mínima pela União em saúde, foi aprovada a desvinculação de $20 \%$ dos recursos do OSS e de impostos para integrar o Fundo Social de Emergência. Esse fundo foi instituído para estabilizar a economia após a implantação do Plano Real e gerar superavit nas contas do governo federal. Posteriormente, seu nome foi alterado para Desvinculação de Receitas da União (DRU) e passou a incidir apenas sobre os recursos do OSS $^{21}$. Em 2016, sua vigência foi prorrogada para 2023, e o percentual de desvinculação aumentou de $20 \%$ para $30 \%$. No período de 2008 a 2016, a DRU foi responsável pela subtração de $\mathrm{R} \$ 698,7$ bilhões do OSS, recursos esses que poderiam ter sido alocados ao financiamento da saúde, da assistência e da previdência social ${ }^{23}$.

No âmbito dos estados, do Distrito Federal e dos municípios, o problema era o de que a CF/88 não definiu patamares mínimos de aplicação em saúde e que não havia até aquele momento sistema de informação que possibilitasse a consolidação do gasto dos entes federados com o SUS, o que constituía desafio adicional às discussões sobre o financiamento. Apesar disso, o fato de a crise financeira do sistema ter sido intensa e explícita naquele momento contribuiu para que, ainda na primeira metade dos anos 1990, fossem apresentadas no Congresso propostas para a vinculação de recursos à saúde pelas três esferas de governo ${ }^{\mathbf{2 4}, 25}$. 
A vinculação foi finalmente instituída com a EC 29, estabelecendo para os estados uma aplicação mínima de recursos em Ações e Serviços Públicos de Saúde (ASPS) de 12\% de seus recursos próprios (o que inclui impostos diretamente arrecadados e as transferências constitucionais e legais); para os municípios, $15 \%$ dos seus recursos próprios; e para o Distrito Federal, $12 \%$ e $15 \%$ de acordo com a natureza da receita, se de base estadual ou municipal, respectivamente. Essas regras permanecem vigentes para os entes subnacionais. No caso da União, a EC 29 definiu como aplicação mínima o valor empenhado no ano anterior, acrescido da variação nominal do PIB ${ }^{26}$.

Mesmo que a vinculação do gasto em ASPS pela EC 29 tenha sido determinante para a ampliação dos recursos alocados ao SUS pelas três esferas de governo, o financiamento do sistema ainda era insuficiente para fazer frente às necessidades de ampliação da oferta de bens e serviços de saúde. Permaneceram desigualdades significativas da despesa por habitante em ASPS entre as unidades federativas e grandes regiões. Os recursos alocados pelo MS por região não conseguiram reduzir as diferenças. Paralelamente, observou-se aumento da participação dos municípios no financiamento do SUS, com diminuição da participação federal27, e ampliação da renúncia fiscal com saúde, que atingiu o valor de $\mathrm{R} \$ 32,3$ bilhões em 201528. Já em 2012, a aprovação da Lei Complementar $\mathrm{n}^{\circ} 141$ frustrou as expectativas quanto à ampliação dos recursos para a saúde. Contudo, foi relevante por melhor delimitar as despesas que podem ser consideradas em ASPS e por ter estabelecido sanções aos entes pelo descumprimento das aplicações mínimas ${ }^{29}$.

Como permanecia o subfinanciamento do sistema, não faltaram propostas legislativas visando ampliar a participação da União no financiamento da saúde, dado que é o ente da Federação dotado de maior capacidade tributária. Dentre essas propostas, merece destaque o Projeto de Lei de Iniciativa Popular (PLP) $n^{\circ}$ 321 de 2013, que propôs a vinculação de $10 \%$ da receita corrente bruta da União à saúde. Esse
PLP era fruto de movimento da sociedade civil que foi chamado de Saúde+10. A despeito de sua importância, o PLP foi desconsiderado pelo Congresso Nacional, que aprovou nova regra de aplicação de recursos pela União, por meio da EC 86 de 2015. Com a EC 86, a União deveria aplicar em ASPS percentuais escalonados de sua Receita Corrente Líquida (RCL), partindo de $13,2 \%$ em 2016 para $15 \%$ em $2020^{29}$.

A recessão econômica iniciada em 2015 trouxe prejuízos ao financiamento federal do SUS em 2016 em virtude da queda de arrecadação sob a vigência da EC 86. No mesmo ano, o fortalecimento da agenda neoliberal após o impeachment da presidente Dilma Rousseff resultou na aprovação da EC 95, emenda do teto de gastos, que congela a despesa primária da União e sua aplicação mínima em ASPS, em termos reais, até $2036^{30}$. Os impactos das medidas contidas na EC 95 para o financiamento do SUS foram alertados antes de sua aprovação ${ }^{\mathbf{3 1}}$ e permanecem sendo denunciados ${ }^{32}$. A perda de recursos federais foi estimada em $\mathrm{R} \$ 22,5$ bilhões entre 2018 e 2020, sendo R $\$ 13,6$ bilhões somente em 201933. Isso revela o potencial de desfinanciamento do SUS pela EC 95 em comparação com a vinculação da aplicação mínima federal em ASPS dada pela EC 86.

A EC 95 representa uma trava para a ampliação do financiamento do SUS, uma vez que não é possível alocar mais recursos para a saúde sem desfinanciar outras políticas no âmbito federal. Como há um teto de gastos para as despesas primárias, as aplicações mínimas em saúde e em educação foram congeladas, e algumas despesas tendem a crescer acima da inflação (benefícios previdenciários, por exemplo), gera-se competição por recursos cada vez mais escassos para financiar outras políticas ${ }^{34}$. Logo, para que a saúde receba mais recursos, outras políticas precisam que eles sejam reduzidos. Ademais, influenciou as mudanças que se operaram em 2017 na forma de transferir recursos para estados e municípios, dos seis blocos de financiamento que traduziam áreas finalísticas de atuação do SUS para dois blocos, custeio 
e investimento, o que revela a priorização da categoria econômica ao invés da finalidade da aplicação dos recursos ${ }^{35}$. Com essas mudanças, o MS foi partícipe do processo de fragilização da indução federal via transferência intergovernamental, um importante mecanismo de coordenação federativa do SUS 35 .

Ao mesmo tempo, a ampliação do empenho de despesas indicadas pelos deputados e senadores nos últimos anos, muito além do que estaria obrigado a executar em razão do orçamento impositivo, explicita essa redução do papel do governo federal na coordenação nacional das políticas de saúde. Para ilustrar, o orçamento impositivo foi de $\mathrm{R} \$ 4,4$ bilhões em 2018, mas as despesas associadas a emendas parlamentares totalizaram $\mathrm{R} \$ 8,8$ bilhões ${ }^{36}$. Essa mudança no interesse de coordenação nacional do sistema se agrava em um contexto histórico de redução da participação federal no financiamento do SUS.

\section{Magnitude e distribuição do gasto e impactos na operação do SUS}

A evolução do gasto total per capita em ASPS deixa evidente o efeito da vinculação das despesas às receitas em contexto de crescimento econômico, no caso dos estados, do Distrito Federal e municípios, e à variação do PIB, no caso da União. O gasto per capita, a valores de 2019, aumentou de $\mathrm{R} \$ 820 \mathrm{em} 2004$ para $\mathrm{R} \$ 1.409 \mathrm{em}$ 2014. A partir de 2015, a estagnação econômica e a EC 95 frearam seu crescimento. Em 2019, o gasto per capita em ASPS foi de R $\$ 1.385$, inferior ao de 2014. A tendência é que diminua ainda mais nos próximos anos sob os efeitos do teto de gastos na União. A crise financeira dos estados e o percentual de recursos próprios aplicados pelos municípios, já bem acima do piso constitucional, apontam para mais dificuldades na expansão do espaço fiscal ${ }^{37}$.

Gráfico 1. Participação dos entes federados no financiamento das despesas em ASPS*. Brasil (2004 - 2019)

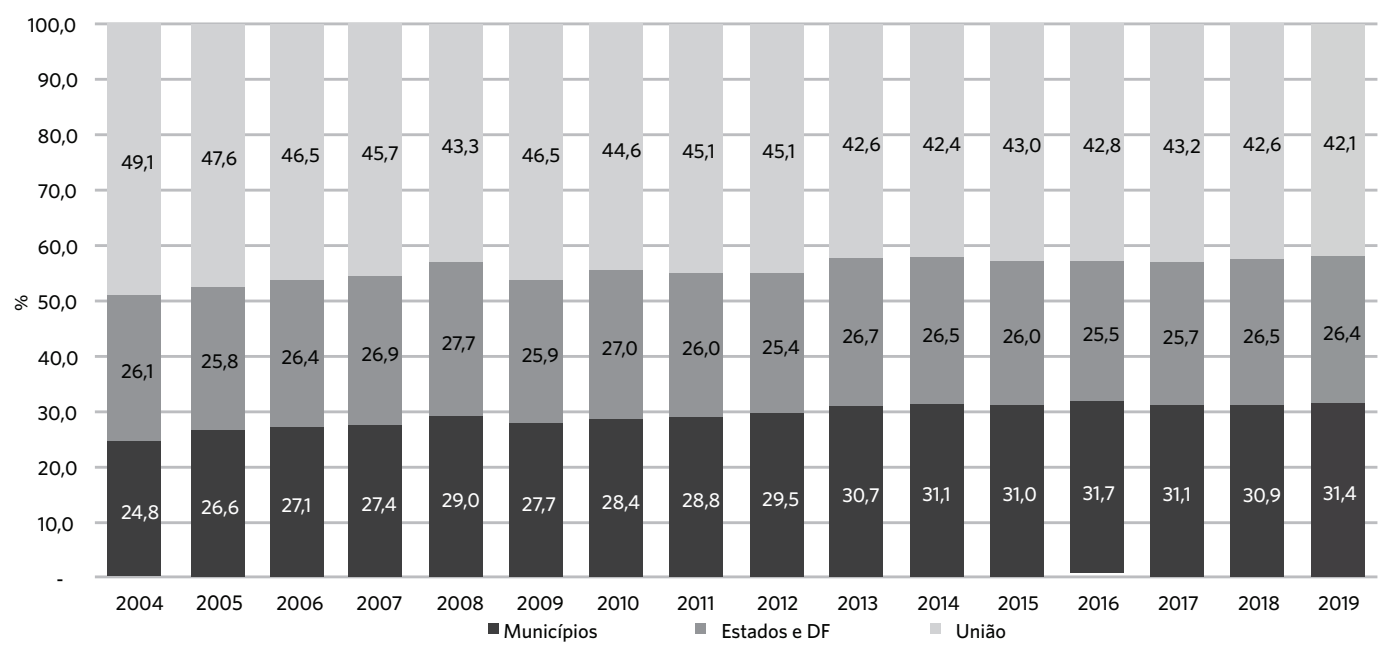

Fontes: Brasil38. Consulta realizada em 13/06/2020.

*ASPS = Ações e Serviços Públicos de Saúde. 
Entre 2004 e 2019, houve aumento da participação dos municípios no financiamento (de $24,8 \%$ para $31,4 \%)$ e redução da participação da União (de 49,1\% para 42,1\%). A participação dos estados manteve-se no patamar de $26 \%$ (gráfico 1) ${ }^{38}$. A redução progressiva da participação federal no financiamento da saúde espelha uma trajetória paradoxal de desresponsabilização do ente federativo com maior poder de arrecadação e coordenação ${ }^{37}$. Essa desresponsabilização reflete-se também na desoneração de atribuições diretas de prestação de serviços à população. Ainda que o regramento legal do SUS não atribua responsabilidades pelo financiamento de funções de atenção à saúde específicas aos níveis de governo individualmente, a análise dos dados consolidados no período entre 2010 e $2014^{39}$ permite identificar um padrão e projetar efeitos de eventuais retrações ou reforços de financiamento dos entes federativos.

Inicialmente, fica clara a importância da União, com contribuições que correspondem, no mínimo, a um terço do financiamento de todas as áreas de atenção (tabela 1$)^{39}$. Com isso, a União é o único ente federativo com participação expressiva no financiamento de todas as funções de atenção à saúde. Isso lhe confere uma posição privilegiada para coordenar as ações de saúde relativamente às esferas subnacionais. A partir da modulação da alocação de recursos, o governo federal, na prática, mantém um papel relevante na proposição do modelo de atenção e até timings das respostas às emergências em saúde pública.

Tabela 1. Alocação de recursos do SUS segundo a finalidade do gasto e participação das esferas de governo. Brasil, média 2010-2014

\begin{tabular}{|c|c|c|c|c|c|}
\hline \multicolumn{2}{|c|}{$\begin{array}{l}\text { Finalidade do gasto segundo função de cuidado de } \\
\text { saúde - System of Health Accounts (SHA) }\end{array}$} & \multirow{2}{*}{$\begin{array}{r}\text { Participação (\%) } \\
\text { da função nas } \\
\text { despesas totais } \\
\text { do SUS }\end{array}$} & \multicolumn{3}{|c|}{$\begin{array}{r}\text { Participação (\%) das esferas de governo } \\
\text { no financiamento das funções }\end{array}$} \\
\hline Código & Descrição da função SHA & & Federal & Estadual & Municipal \\
\hline HC 1.1 & $\begin{array}{l}\text { Atenção curativa em regime de } \\
\text { internação }\end{array}$ & 22,0 & 39 & 48 & 13 \\
\hline HC 1.3 .1 & $\begin{array}{l}\text { Atenção curativa ambulatorial bá- } \\
\text { sica }\end{array}$ & 14,2 & 34 & 6 & 61 \\
\hline HC 1.3.2 & Atenção ambulatorial saúde bucal & 1,9 & 34 & 6 & 60 \\
\hline HC 1.3 .3 & Atenção ambulatorial especializada & 14,0 & 51 & 26 & 23 \\
\hline HC 1.4 & Atenção curativa domiciliar & 0,8 & 33 & 5 & 63 \\
\hline $\mathrm{HC} 2$ & Atendimentos de reabilitação & 1,6 & 73 & 9 & 18 \\
\hline $\mathrm{HC} 3$ & Cuidados de longo prazo & & 48 & 26 & 26 \\
\hline $\mathrm{HC} 4$ & $\begin{array}{l}\text { Atividades complementares ao } \\
\text { diagnóstico e tratamento }\end{array}$ & 10,9 & 33 & 42 & 25 \\
\hline $\mathrm{HC} 5$ & Medicamentos e produtos médicos & 6,9 & 74 & 13 & 14 \\
\hline HC 6 & $\begin{array}{l}\text { Vigilância, promoção e prevenção } \\
\text { em saúde }\end{array}$ & 11,4 & 46 & 10 & 44 \\
\hline \multicolumn{2}{|c|}{ Demais funções e não classificadas } & 16,3 & & & \\
\hline \multicolumn{2}{|c|}{ Total da Despesa Corrente em Saúde } & 100,0 & 44 & 26 & 30 \\
\hline
\end{tabular}


Nos segmentos em que a responsabilidade pelo financiamento fica concentrada em um único ente federativo, cria-se uma maior vulnerabilidade a quedas de financiamento por parte desse ente. A União, por exemplo, tem sido a principal financiadora de medicamentos e produtos médicos distribuídos a pacientes do SUS (73\% do total entre 2010 e 2014$)^{40}$, o que explicita sua centralidade nos resultados da assistência farmacêutica, mas também fragiliza essa função da atenção em situações de retração do financiamento federal.

A União aportou também a maior parte dos recursos para atendimentos ambulatoriais especializados ( $51 \%$ das despesas da função) entre 2010 e 2014. Entretanto, já nesse mesmo período, o financiamento municipal para essa função foi o que mais cresceu entre os entes federativos, um possível indício de tentativa dos municípios de preencherem lacunas de financiamento em uma área com longos tempos de espera que restringem a integralidade da atenção $0^{\mathbf{4 1}}$.

O padrão de alocação de gastos do SUS mostra uma responsabilidade compartilhada de União e municípios nas funções de atendimento ambulatorial básico e vigilância, prevenção e promoção, com literal ausência da participação dos estados. Ao mesmo tempo, os estados detinham os maiores gastos nas áreas de exames diagnósticos e internações, concentrando financiamento em funções ligadas à média e alta complexidade (tabela 1).

O padrão de alocação de recursos contribui para reforçar uma segmentação de competências assistenciais federativas e repercute sobre a capacidade de resposta a emergências sanitárias. Em situações que exijam respostas rápidas, como na pandemia de Covid-19, a segmentação aumenta a necessidade de coordenação.

As definições para fluxos assistenciais na pandemia geram também demandas diferenciadas sobre as funções de atenção e contribuem para conferir protagonismos distintos às esferas federativas nos vários momentos. No início da pandemia, a necessidade de isolamento social para conter o avanço da doença motivou a recomendação à população para procurar atendimento médico apenas se o quadro clínico respiratório se agravasse. Essa diretriz deu destaque à demanda por cuidados críticos e ao protagonismo dos estados, que dominam o segmento de média e alta complexidade e a gestão da oferta de leitos de cuidados críticos. Em outubro, o governo lançou o Programa Vigiar SUS com previsão de $\mathrm{R} \$ 1,5$ bilhão ${ }^{42}$, com foco somente na Covid19, o qual, a depender de sua condução, pode agravar o desfinanciamento da vigilância de outras doenças e agravos ${ }^{\mathbf{4 3}}$. Ao mesmo tempo, os estados podem buscar protagonismo investindo em ampliação de testes diagnósticos, área na qual já alocam recursos.

Outro padrão de alocação que merece ser analisado são os fluxos de recursos para prestadores de serviços segundo natureza jurídica pública ou privada. O Brasil caracteriza-se por uma intensa presença de prestadores privados de serviços de saúde em seu território ${ }^{44}$. Esses prestadores têm sido tradicionalmente contratados pelo SUS para atendimento especializado e de alto custo, áreas onde o financiamento federal permanece expressivo ${ }^{45}$.

A Conta Satélite de Saúde indica um consumo de serviços privados de saúde pelo SUS que variou de $\mathrm{R} \$ 27,1$ bilhões a valores correntes (2010) a R $\$ 43,6$ bilhões (2017), com uma média no período que correspondeu a $17,5 \%$ dos serviços privados no País ${ }^{15}$. Com a expansão do modelo de Organizações Sociais e outras formas de contratualização, vem crescendo a atuação do setor privado no SUS em outras áreas ${ }^{\mathbf{4 5}}$.

Nova no elenco de relações do SUS com prestadores de serviços e empresas privadas é a emergência do fenômeno da filantropia de desastre durante a pandemia de Covid-1946. Até 24 de julho, foram doados R 6,4 bilhões por empresas e pessoas físicas, valor superior à aplicação direta do MS para enfrentamento da pandemia ${ }^{47}$. Em estados como o Rio de Janeiro, testemunhamos grupos de doadores, inclusive pessoas físicas e empresas da saúde e de outros ramos, financiando e operando hospitais de campanha e reativando leitos em 
hospitais universitários mediante a aquisição de equipamentos e insumos ${ }^{48}$.

Em uma leitura rigorosamente empresarial, essas são situações que embutem oportunidades de aprendizado tecnológico e de governança para as empresas, além de mostrar uma imagem de responsabilidade social e criar um potencial de protagonismo no cenário pós-pandêmico ${ }^{46}$. Altruísmo não é propriamente um atributo de empresas ${ }^{49}$, mas essa mobilização permitiu a ágil alocação de recursos fundamentais no SUS em um momento crítico de instalação da pandemia em um local em que houve falhas graves de atuação do Estado. Isso convida a examinar os recursos públicos novos alocados para ações e serviços de saúde de enfrentamento da pandemia.

\section{Novos recursos ante a pandemia}

No contexto da pandemia, a primeira medida adotada para o financiamento federal das ações e serviços de saúde, a Medida Provisória 924, de 13 de março, não representou aumento da dotação orçamentária, mas um remanejamento de recursos do orçamento do MS para 2020. Somente no início de abril foi editada a primeira medida provisória contendo crédito extraordinário, da ordem de $\mathrm{R} \$ 9,4$ bilhões. Até outubro, foram publicadas 11 medidas provisórias com destinação de recursos para o MS totalizando R \$ 44,1 bilhões, sendo R\$ 38,3 bilhões de recursos novos; desse valor, $\mathrm{R} \$ 22,8$ bilhões são financiados por operações de crédito internas. A ação orçamentária 21C0, criada para execução dos recursos para enfrentamento da Covid-19, representa 99,1\% do total alocado pelo MS para a pandemia ${ }^{50}$.

O que chama atenção na evolução da execução orçamentária é o grande aumento da dotação orçamentária ter acontecido somente a partir da segunda quinzena de maio, alguns dias após a segunda mudança no comando do MS em menos de um mês, quando assume o ministro interino General Pazuello, em um momento em que o contágio já era muito expressivo (gráfico 2). Ainda mais relevante foi a lentidão da execução orçamentária, bastante aquém do esperado e do necessário, considerando a urgência das demandas relacionadas com a pandemia (gráfico 3).

Gráfico 2. Execução orçamentária da ação $21 \mathrm{CO}$ 'Enfrentamento da Emergência de Saúde Pública de Importância Internacional Decorrente do Coronavírus' de 7 de abril a 30 de outubro, valor total em R $\$$ bilhões

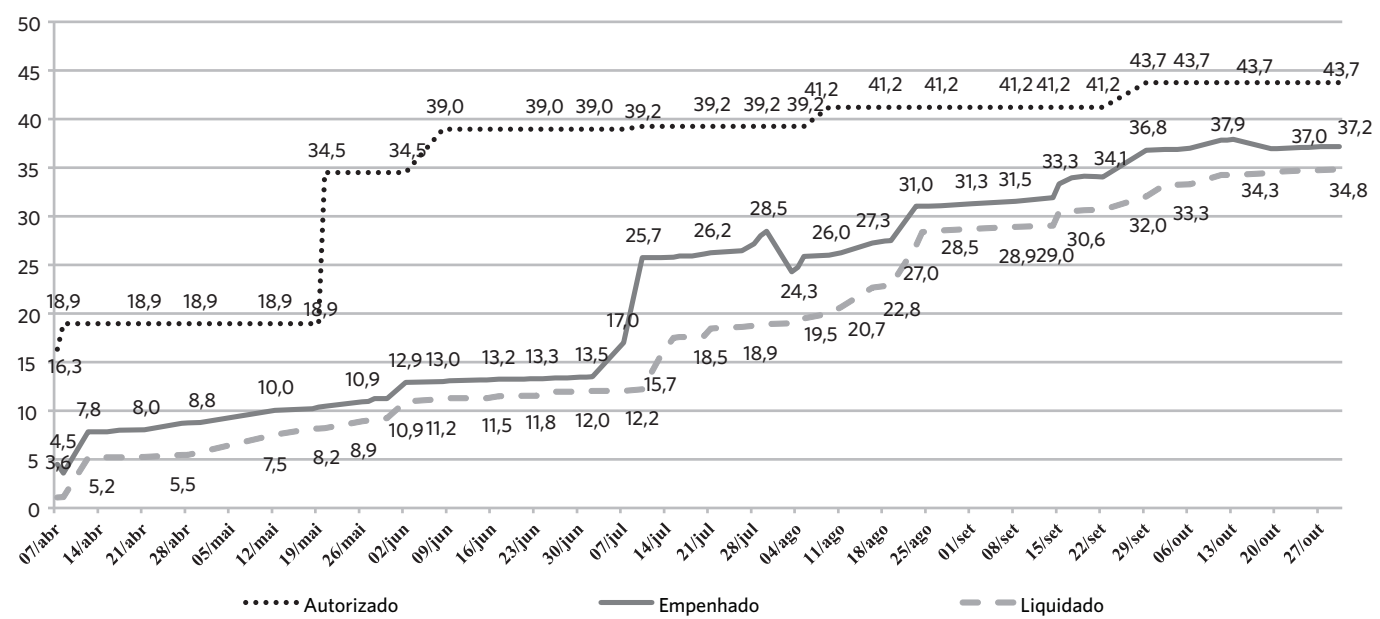

Fonte: Funcia et al.50 
Gráfico 3. Despesa liquidada na ação $21 \mathrm{CO}$ por modalidades de aplicação selecionadas, de 7 de abril a 30 de outubro de 2020, em R\$ bilhões

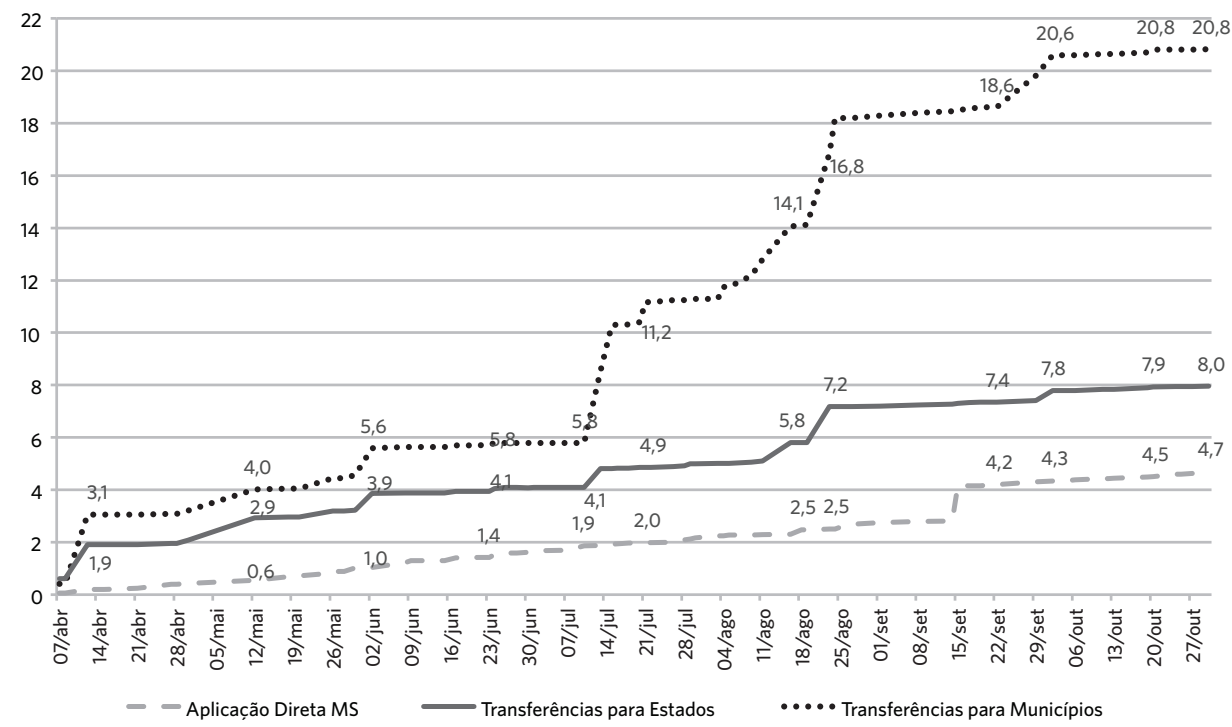

Fonte: Funcia et al.50

Mesmo as transferências fundo a fundo para estados e municípios, que deveriam depender apenas de pactuação entre os gestores na Comissão Intergestores Tripartite (CIT), sem os embaraços que envolvem a aplicação direta de recursos, têm baixa execução. No final de junho, após quase 100 dias de decretação de estado de calamidade pública, de uma dotação orçamentária disponível de R\$10,0 bilhões para os governos estaduais, apenas R\$ 3,9 bilhões (39,5\%) haviam sido transferidos. No caso dos governos municipais, de uma dotação de R\$16,9 bilhões, apenas $\mathrm{R} \$$ 5,6 bilhões (33,9\%) haviam sido repassados. Somente a partir de julho e até meados de agosto é que os recursos foram transferidos em maior volume para estados e municípios, quando o País já contabilizava mais de 100 mil óbitos em decorrência do novo coronavírus.

Esses resultados mostram que, ainda que tenha sido aprovado o Orçamento de Guerra ${ }^{51}$ e existam recursos previstos no orçamento para o combate à pandemia, aparentemente, faltou empenho do governo federal para executá-los e alocá-los no ritmo necessário em uma emergência em saúde pública, prejudicando as ações de combate à pandemia nas três esferas de governo. Isso ocorre mesmo quando a execução depende apenas de pactuação e vontade política, como é o caso das transferências para os entes subnacionais, executores diretos das ações.

Ainda com relação às transferências, observa-se que a descentralização dos recursos para a Covid-19 manteve o curso tradicional de maior direcionamento para municípios, com menor participação dos estados e das aplicações diretas. Ao mesmo tempo, as demandas por investimentos para cobrir vazios assistenciais estavam fortemente associadas à atenção hospitalar e à alta complexidade, em que o papel dos estados é considerado central. Ainda que se pudesse pensar em um reforço da coordenação entre estados e municípios por meio do fomento à organização das redes regionalizadas, esse não foi o caminho seguido pelas transferências federais nem mesmo em um momento como o da pandemia. 
Isso indica a dificuldade de planejamento em um momento em que a necessidade era clara, bem como a relevância de avançar na regionalização da saúde ${ }^{\mathbf{5 2}}$.

É preciso também organizar o SUS para operar suas atividades de prestação de serviços no novo contexto pandêmico, embora nossa tradição seja a de operação em contextos endêmicos, e estimar quanto isso custa. O plano de enfrentamento da Covid-19 proposto por 15 entidades de saúde coletiva e de profissionais de saúde ${ }^{53}$ destaca a importância do SUS. São defendidas a implementação de estratégias de rede regionalizadas, a expansão e qualificação da atenção primaria, além da garantia de acesso regulado à atenção especializada. Entram em pauta também, de forma talvez inédita, a ampliação de serviços hospitalares e a necessidade de reforçar os sistemas logísticos, tão demandados nas emergências dessa natureza.

Em um horizonte imediato, teríamos que garantir recursos para atender casos urgentes adiados por temor do vírus, composto principalmente pelo acompanhamento de doenças crônicas e, em especial, por procedimentos oncológicos. Em um momento subsequente, recuperar os procedimentos eletivos - cirurgias para tratamento de hérnias, cataratas, colecistectomias e similares.

Em um contexto de pandemia, a atenção ao financiamento de duas funções em especial precisa ser intensificada - vigilância em saúde e emergência e cuidados críticos, essas últimas funções ligadas ao suporte à vida. Isso implica, no âmbito mais amplo da saúde pública, reorganizar o Sistema Nacional de Vigilância em Saúde, em que a literatura vem de longa data apontando falhas no processo de descentralização ${ }^{\mathbf{5 4}, 55}$. É preciso também integrar a Atenção Primária à Saúde (APS) às medidas de vigilância pandêmica, recomendação expressa do Plano Nacional de Enfrentamento à (sic) Pandemia da Covid ${ }^{53}$.

Embora a aposta imediata no poder mágico dos grandes breakthroughs tecnológicos ligadas à telemedicina tenha prosperado em outros países $^{56}$, ela pode ainda não ser viável neste momento. Provavelmente, haverá iniciativas locais nesse sentido, mas um grande esforço de padronização de plataformas tecnológicas talvez não esteja ao alcance da capacidade de financiamento do SUS.

Outra medida relevante seria ajustar a capacidade e a ociosidade planejadas em emergência e Unidade de Terapia Intensiva (UTI) para atender com rapidez às emergências de saúde pública. Embora o Brasil conste como o país com maior número de leitos de UTI na América Latina ${ }^{57}$, mais de 30 milhões de pessoas residiam a mais de $120 \mathrm{~km}$ de unidades de cuidados intensivos. A distribuição de serviços de emergência no Brasil não facilita o acesso da população ${ }^{58}$.

\section{Considerações finais}

Os debates sobre o subfinanciamento do SUS e suas fragilidades não são recentes. A pandemia levou o mundo todo a refletir sobre como garantir recursos para financiar os sistemas de saúde ${ }^{59}$. No Brasil, os problemas se multiplicam na tentativa de garantir um sistema de saúde universal, integral e equânime, bem como as dificuldades para sua gestão tripartite, agravadas pela ausência de uma coordenação federal.

A parcela do financiamento público continua inferior ao privado (menos de $45 \%$ em 2017). A participação dos entes subnacionais no financiamento da saúde já vinha se ampliando muito antes da pandemia. No contexto da pandemia, os governos estaduais, que têm a menor participação no financiamento do SUS, tiveram que assumir o protagonismo das respostas à crise sanitária, visto que o esforço imediato do governo federal com novos recursos e de coordenação ficou muito aquém do necessário ao seu enfrentamento.

As principais fontes de receitas tributárias estão concentradas na União, com mais da metade dos gastos públicos em saúde sendo financiados por tributos arrecadados por esse 
ente federado. Como nos alertam Silveira et al., com as perdas imposta pela EC 95, pode haver pressão sobre os governos estaduais, mas sendo pouco provável que possíveis ganhos de arrecadação desses entes sejam redirecionados para a saúde dadas as dificuldades que esses atravessam ${ }^{60}$. Além disso, em uma grande crise econômica e social, as principais respostas têm que vir de políticas nacionais, macroeconômicas e sociais. Não cabe aos governos locais esse papel, até porque isso amplia ainda mais as reconhecidas desigualdades regionais do País.

As medidas macroeconômicas que poderiam garantir maior isolamento social foram tomadas quase dois meses depois do primeiro caso. Ao mesmo tempo, o aumento da dotação orçamentária federal não foi seguido por uma rápida execução desses recursos. Adicionalmente, o momento também não foi utilizado para pensar a organização de uma rede regionalizada, considerando que houve necessidade de investimentos expressivos para cobrir vazios assistenciais.

Outra preocupação que se coloca para além das questões imediatas de resposta à pandemia refere-se ao seu impacto em gastos futuros. O retorno deve ser lento e em um regime de operação diferente do que conhecíamos nos serviços de saúde, com mais necessidade de cuidados e proteção ${ }^{61}$. Pode haver grandes variações regionais, com forte influência do timing, da gravidade do quadro pandêmico e dos recursos disponíveis para recuperação nas regiões.

No caso brasileiro, diante do cenário econômico de recessão arrastada com que o País já convivia antes da pandemia, evoluindo para franca depressão no período pós-pandêmico, em que medida o financiamento do SUS será priorizado? Somente a União tem capacidade de se endividar, o que cria restrições à atuação de estados e municípios.

Lamentavelmente, enquanto a saúde é sempre citada no topo da preocupação dos eleitores ${ }^{62,63}$, essa prioridade não se reflete no debate político, como se as eleições não dissessem respeito à vida cotidiana das pessoas. $\mathrm{O}$ voto no Brasil colônia, regido pelas Ordenações do Reino, teria, segundo Cajado, a função de "garantir que a sociedade funcione em ordem: incluindo, pressupondo e reforçando as tradições"64(23). Seguindo a tradição colonial, parece que essa continua a ser a função primordial das eleições brasileiras.

No quadro caótico que se anuncia para o financiamento das políticas públicas e intensificação de uma lógica de 'escolha de Sofia' que se institui entre elas, a intensificação da narrativa de insegurança e violência social pode substituir o peso da narrativa da corrupção na moldagem do marketing político, com a pauta de segurança invadindo com muito peso a disputa de recursos já escassos.

Uma preocupação central é o enorme aumento do deficit público consequente à pandemia, que tenderá a comprometer o financiamento disponibilizado ao SUS. Se a pressão do deficit público tem justificado as mais recentes legislações que reduziram o volume de recursos alocado ao sistema, seria ingênuo imaginar que essa pressão irá diminuir. Com a queda do PIB brasileiro em 2020, os gastos em saúde como proporção do PIB tenderão a aumentar, ainda que não exista aumento ou haja redução das despesas em termos reais. Esse comportamento do indicador tende a dar a impressão e criar as bases para falar em gasto excessivo ${ }^{65}$.

Diante disso, amplia-se a agenda de pesquisa que precisamos contemplar: como será reconfigurado o financiamento do SUS, considerando-se as participações das esferas no aporte de recursos, as especializações funcionais dos níveis de governo e o direcionamento de fluxos financeiros para infraestrutura pública ou privada? Qual será o papel dos níveis de atenção e dos estabelecimentos? Quão intensas serão as forças do mercado para direcionar essas opções? Quais as implicações de protagonismo maior dos governos estaduais, que não têm menor participação no financiamento da APS? Quais serão os rearranjos federativos possíveis do financiamento e das responsabilidades assistenciais? 


\section{Aviso legal}

As opiniões emitidas neste artigo são de exclusiva e inteira responsabilidade dos autores, não exprimindo, necessariamente, o ponto de vista das instituições à qual se vinculam.

\section{Colaboradores}

Servo LMS (0000-0003-0770-7378)*, Santos MAB (0000-0002-7547-3537)*, Vieira FS (0000-0001-7377-7302)* e Benevides RPS (0000-0001-6978-2475)* contribuíram igualmente para a elaboração do manuscrito.

\section{Referências}

1. Delaterra E, Mir D, Graf T, et al. Tracking the onset date of the community spread of SARS-CoV-2 in Western Countries. Mem Inst Oswaldo Cruz. Rio de Janeiro: medRxiv; 2020.

2. Conselho Nacional de Secretários de Saúde. Painel Conass: Covid-19 [internet]. 2020. [acesso em 2020 jun 12]. Disponível em: https://bit.ly/37rYQpw.

3. European Centre for Disease Prevention and Control. Situation updates on Covid-19. [acesso em 2020 jun 12]. Disponível em: https://bit.ly/31mZtQ7.

4. Conti T. Crise Tripla do Covid-19: um olhar econômico sobre políticas públicas de combate à pandemia, abril, 2020 [internet]. [acesso em 2020 jun 15]. Disponível em: https://bit.ly/2ZeZbYX.

5. UOL. Coronavírus: Bolsonaro fala em onda enorme de desemprego e "põe no colo" de governadores. UOL. 2020 jun 7. [acesso em 2020 jun 15]. Disponível em: https://bit.ly/2NyOHji.

6. Greenstone M, Nigam V. Does Social Distancing Matter? [internet]. 2020. [acesso em 2020 jun 15]. Disponível em: http://dx.doi.org/10.2139/ssrn.3561244.
7. Hafiz H, Oei S, Ring D, et al. Regulating in Pandemic: Evaluating Economic and Financial Policy Responses to the Coronavirus Crisis. Boston College Law School Legal Studies Research Paper. 2020; (527):1-10.

8. Acemoglu D, Chernozhukov V, Werning I, et al. Optimal targeted lockdowns in a multi-group SIR model [internet]. 2020. [acesso em 2020 jun 15]. Disponível em: https://economics.mit.edu/files/19698.

9. Moraes R. Medidas legais de incentivo ao distanciamento social: comparação das políticas e governos estaduais e prefeituras das capitais no Brasil [internet]. 2020. [acesso em 2020 jun 15]. Disponível em: https://bit.ly/2BkjZpI.

10. Rache B, Rocha R, Nunes L, et al. Para além do custeio: necessidades de investimento em leitos de UTI no SUS sob diferentes cenários da Covid-19. São Paulo: IEPS; 2020. (Nota Técnica, 7). [acesso em 2020 jun 18]. Disponível em: https://bit.ly/3iaYJ6n.

11. Noronha K, Guedes GR, Turra CM, et al. The COVID-19 pandemic in Brazil: analysis of supply and demand of hospital and ICU beds and mechanical ventilators under different scenarios. Cad. Saúde Pública. 2020; 36(6):e00115320.
*Orcid (Open Researcher and Contributor ID). 
12. Castro MC, Carvalho LR, Chin T, et al. Demand for hospitalization services for COVID-19 patients in Brazil [internet]. 2020. [acesso em 2020 jun 15]. Disponível em: https://www.medrxiv.org/content/10.11 01/2020.03.30.20047662v1.

13. Pereira RHM, Braga CKV, Servo LMS, et al. Mobilidade urbana e o acesso ao sistema único de saúde para casos suspeitos e graves de CovidCovid-19 nas vinte maiores cidades do Brasil [internet]. [acesso em 2020 jun 18]. Disponível em: https://bit.ly/2NEpguM.

14. World Health Organization. Monitoring the building blocks of health systems: a handbook of indicators and their measurement strategies. Geneve: WHO; 2010.

15. Instituto Brasileiro de Geografia e Estatística. Conta-satélite de saúde: Brasil: 2010-2017. Rio de Janeiro: IBGE; 2019. [acesso em 2020 jun 18]. Disponível em: https://bit.ly/3fEjVBd.

16. Brasil. Constituição, 1988. Constituição da República Federativa do Brasil. Brasília, DF: Senado Federal; 1988.

17. Brasil. Emenda Constitucional $n^{\circ} 29$, de 13 de setembro de 2000. Altera os arts. 34, 35, 156, 160, 167 e 198 da Constituição Federal e acrescenta artigo ao Ato de disposições Constitucionais Transitórias, para assegurar os recursos mínimos para o financiamento das ações e serviços públicos de saúde. Diário Oficial da União. 14 Set 2000.

18. Brasil. Lei Complementar $\mathrm{n}^{\circ}$ 141, de 13 de janeiro de 2012. Regulamenta o $93^{\circ}$ do art. 198 da Constituição Federal para dispor sobre os valores mínimos a serem aplicados anualmente pela União, Estados, DF e Municípios em ações e serviços públicos de saúde; estabelece os critérios de rateio dos recursos de transferências para a saúde e as normas de fiscalização, avaliação e controle das despesas com saúde nas três esferas de governo. Diário Oficial da União. 13 Jun 2012.

19. Organização Pan-Americana da Saúde. Financiamento público de saúde [internet]. Brasília, DF: MS; 2013. [acesso em 2020 jun 12]. Disponível em: https://bit. ly/3hfiQQu.
20. Mendes A, Marques R. A saúde pública sob a batuta da nova ordem. In: Marques R, Ferreira MRJ, organizadores. O Brasil sob nova ordem: a economia brasileira contemporânea. São Paulo: Saraiva; 2010. p. 267-286.

21. Jorge AT. Apontamentos acerca da desvinculação de receitas da União (DRU). RFPTD 2018; 6(6):1-29.

22. Brasil. Emenda constitucional $n^{0} 93$, de 8 de setembro de 2016. Altera o Ato das Disposições Constitucionais Transitórias para prorrogar a desvinculação de receitas da União e estabelecer a desvinculação de receitas dos Estados, DF e Municípios [internet]. 2016. [acesso em 2020 jun 12]. Disponível em: https:// bit.ly/3bMba4T.

23. Salvador ES. O desmonte do financiamento da seguridade social em contexto de ajuste fiscal. Serv. Soc. Soc [internet]. 2017 [acesso em 29 out 2020]; 130:426446. Disponível em: http://dx.doi.org/10.1590/01016628.117.

24. Marques RM. O financiamento do sistema público de saúde brasileiro. Santiago: CEPAL; 1999. (Série Financiamento del Desarollo, n. 82). [acesso em 2020 jun 12]. Disponível em: https://bit.ly/2MT7T9j.

25. Servo LMS, Piola SF, Paiva AB, et al. Financiamento e gasto público de saúde: histórico e tendências. In: Melamed C, Piola SF, organizadores. Políticas públicas e financiamento federal do Sistema Único de Saúde. Brasília, DF: Ipea; 2011. p. 85-108.

26. Piola SF, Paiva AB, Sá EB, et al. Financiamento público da saúde: uma história à procura de rumo [internet]. Brasília, DF: Ipea; 2013. (Texto para Discussão n. 1846). [acesso em 2020 jun 12]. Disponível em: https://bit.ly/2UzozqE.

27. Piola SF, Benevides RPS, Vieira FS. Consolidação do gasto com ações e serviços públicos de saúde: trajetória e percalços no período de 2003 a 2017. Rio de Janeiro: Ipea; 2018. (Texto para Discussão n. 2439). [acesso em 2020 jun 12]. Disponível em: https://bit. ly/30qQlcN. 
28. Ocké-Reis CO, Fernandes AMP. Descrição do gasto tributário em saúde: 2003 a 2015. Brasília, DF: Ipea; 2018. (Nota Técnica n. 48). [acesso em 2020 jun 12]. Disponível em: https://bit.ly/2Yt5pUH.

29. Vieira FS, Piola SF, Benevides RPS. Vinculação orçamentária do gasto em saúde no Brasil: resultados e argumentos a seu favor. Brasília, DF: Ipea; 2019. (Texto para Discussão n. 2516). [acesso em 2020 jun 12]. Disponível em: https://bit.ly/2JO4lUp.

30. Sá EB, Vieira FS, Benevides RPS, et al. Saúde. Polít. Soc.: acomp. Análise [internet]. 2018; (25):111-156. [acesso em 2020 jun 12]. Disponível em: https://bit. ly/2XUfsCU.

31. Vieira FS, Benevides RPS. Os impactos do Novo Regime Fiscal para o financiamento do Sistema Único de Saúde e para a efetivação do direito à saúde no Brasil. Brasília, DF: Ipea; 2016. (Nota Técnica, n. 28). [acesso em 2020 jun 12]. Disponível em: https://bit. $\mathrm{ly} / 3 \mathrm{hm} 36 \mathrm{Lu}$.

32. Funcia FR, Ocké-Reis CO. Efeitos da política de austeridade fiscal sobre o gasto público federal com saúde. In: Rossi P, Dweck E, Oliveira AM, organizadores. Economia para poucos: impactos sociais da austeridade e alternativas para o Brasil. São Paulo: Autonomia Literária; 2018. p. 83-97.

33. Santos L, Funcia FR. Histórico do financiamento do SUS: evidências jurídico-orçamentárias do desinteresse governamental federal sobre a garantia do direito fundamental à saúde. Doming. da Saúde. 2020 [acesso em 2020 out 29]; (21):1-10. Disponível em: https://bit.ly/36pNN1D.

34. Friedrich E. Austeridade e retrocesso: finanças públicas e política fiscal no Brasil [internet]. São Paulo: Fórum, 21; Fundação Friedrich Ebert Stiftung; 2016. [acesso em 2020 out 20]. Disponível em: https://bit. ly/3e7FlFN.

35. Jaccoud L, Vieira FS. Federalismo, integralidade e autonomia no SUS: desvinculação da aplicação de recursos federais e os desafios da coordenação. Rio de Janeiro: Ipea; 2018. (Texto para Discussão n. 2399). [acesso em 2020 jun 10]. Disponível em: https://bit. ly/2zqLjlu.

36. Piola SF, Vieira FS. As emendas parlamentares e a alocação de recursos federais no Sistema Único de Saúde. Rio de Janeiro: Ipea; 2019. (Texto para Discussão n. 2497). [acesso em 2020 jun 12]. Disponível em: https://bit.ly/2Ynlivy.

37. Pinto EG. Guerra fiscal de despesas na pactuação federativa do SUS: um ensaio sobre a instabilidade de regime jurídico do piso federal em saúde. In: Santos AO, Lopes LT, organizadores. Coletânea direito à saúde: dilemas do fenômeno da judicialização da saúde. Brasília, DF: Conass; 2018. p. 92-106.

38. Brasil. Siops - Sistema de Informações sobre Orçamentos Públicos em Saúde para despesas empenhadas pelos estados, DF e municípios. Siga Brasil para despesas empenhadas da União.

39. Brasil. Ministério da Saúde; Fiocruz. Conta do SUS na perspectiva da contabilidade internacional. Brasília, DF: Ministério da Saúde; Fiocruz; 2018.

40. Almeida ATC, Sá EB, Vieira FS, et al. Impacto do Programa Farmácia Popular do Brasil sobre a saúde de pacientes crônicos. Rev. Saúde Púb. 2019; 53(20):1-11.

41. Giovanella L, Mendonça MHM, Almeida PF, et al. Saúde da família: limites e possibilidades para uma abordagem integral de atenção primária à saúde no Brasil. Ciênc. Saúde Colet. [internet]. 2009 [acesso em 2020 ago 31]; 14(3):783-794. Disponível em: https://www.scielo.br/scielo.php?script=sci_arttext\& pid $=$ S1413-81232009000300014.

42. Brasil. Ministério da Saúde. Programa Vigiar Saúde é lançado pelo Ministério da Sáude [internet]. 2020. [acesso em 2020 ago 31]. Disponível em: https://www.gov.br/pt-br/noticias/saude-e-vigilancia-sanitaria/2020/10/programa-vigiar-sus-e-lancado-pelo-ministerio-da-saude.

43. Vieira FS, Benevides RPS. Gasto federal com vigilância em saúde na última década e a necessidade de reforço do orçamento do Ministério da Saúde para en- 
frentamento à pandemia pelo coronavírus. Brasília, DF: Ipea; 2020. (Nota Técnica n. 61). Disponível em: https://bit.ly/2TKVLuY.

44. Santos IS, Santos MAB, Borges DCL. Mix Público-Privado no Sistema de Saúde Brasileiro: realidade e futuro do SUS. In: Fundação Oswaldo Cruz. A saúde no Brasil em 2030 - prospecção estratégica do sistema de saúde brasileiro: estrutura do financiamento e do gasto setorial. Rio de Janeiro: Fiocruz; Ipea; Ministério da Saúde; 2013. Vol. 4. p.73-131.

45. Santos MAB, Servo LMS. A provisão dos serviços e ações do SUS: participação de agentes públicos e privados e formas de produção/remuneração dos serviços. In: Marques R, Piola S, Roa AC, organizadores. Sistema de saúde no Brasil: organização e financiamento. Rio de Janeiro; Brasília, DF: Abres; Ministério da Saúde; Opas/OMS; 2016. p. 205-45.

46. Mithani MA. Liability of foreignness, natural disasters, and corporate philanthropy. J. Inter. Business Studies. 2017; 48(8):941-963.

47. Galina D, Bernardo JC. Empresas brasileiras continuam doando para mitigar os efeitos da covid-19 [internet]. Forbes, 24 out 2020. [acesso em 2020 ago 31]. Disponível em: https://bit.ly/320t812.

48. Sartor V. Rede Dor e GE Healthcare fecham parceria na luta contra da Covid-19 [internet]. Grupo Mídia, 2020 abr 20. [acesso em 2020 jun 16]. Disponível em: https://bit.ly/2COaL5G.

49. Friedman M. The social responsibility of business is to increase its profits. In: Corporate ethics and corporate governance. Springer; Heidelberg; 2007. p. 173-178.

50. Funcia FR, Benevides RPS, Ocké-Reis CO. Boletim da Comissão de Orçamento e Financiamento do Conselho Nacional de Saúde - Cofin/CNS de 28/10/2020 [internet]. 2020. [acesso em 2020 jun 16]. Disponível em: https://bit.ly/35R4qkT.

51. Brasil. Emenda Constitucional no 106, de 07 de maio de 2020. Institui regime extraordinário fiscal, finan- ceiro e de contratações para enfrentamento de calamidade pública nacional decorrente de pandemia. Diário Oficial da União. 8 Maio 2020.

52. Lima LD, Pereira AMM, Machado CV. Crise, condicionantes e desafios de coordenação do Estado federativo brasileiro no contexto da COVID-19. Cad. Saúde Pública. 2020; 36(7):e00185220.

53. Associação Brasileira de Saúde Coletiva. Plano Nacional de Enfrentamento à Pandemia da COVID-19. Contribuição das organizações que compõem a FRENTE PELA VIDA e atuam no campo da Saúde à sociedade brasileira [internet]. 2020. [acesso em 2020 out 26]. Disponível em: https://bit.ly/3ecjGfX.

54. Lucena RCB. A descentralização na vigilância sanitária: trajetória e descompasso. Rev. Adm. Públ. 2015; 49(5):1107-1120.

55. De Seta MH, Dain S. Construção do Sistema Brasileiro de Vigilância Sanitária: argumentos para debate. Ciênc. Saúde Colet. 2020; 15(supl3):3307-3317.

56. Ahmed S, Sanghvi K, Yeo D. Telemedicine takes centre stage during COVID-19 pandemic. BMJ Innovations [internet]. 2020 [acesso em 2020 out 26]; (0):1-3. Disponível em: http://dx.doi.org/10.1136/ bmjinnov-2020-000440.

57. Organização para a Cooperação e Desenvolvimento Econômico. Health at a Glance 2020. Paris: OCDE; 2020.

58. Rocha TAH, Silva NC, Amaral PV, et al. Access to emergency care services: a transversal ecological study about Brazilian emergency health care network. Public Health, 2017; 153:9-15.

59. Tandon A, Roubal T, McDonald L, et al. Economic Impact of COVID-19: Implications for Health Financing in Asia and Pacific. Washington, DC: Banco Mundial; 2020.

60. Silveira FS, Noronha SG. Funcia FR, et al. Os fluxos financeiros no financiamento e no gasto em Saúde no Brasil [internet]. Rio de Janeiro: Fundação Oswaldo 
Cruz; 2020. [acesso em 2020 out 20]. Disponível em: https://bit.ly/2TDGifQ.

61. O'Connor CM, Anoushiravani AA, DiCaprio MR, et al. Economic Recovery After the COVID-19 Pandemic: Resuming Elective Orthopedic Surgery and Total Joint Arthroplasty. J Arthroplasty. 2020; 35(7S):S32-S36.

62. Gelape L. Saúde é o problema mais citado pelos eleitores nos estados do país, apontam pesquisas Ibope [internet]. G1. 2018 ago 26. [acesso em 2020 jun 18]. Disponível em: https://glo.bo/3eH6uzO.

63. Associação Brasileira de Saúde Coletiva. Pesquisa revela que saúde pública é a principal preocupação dos eleitores [internet]. 2020. [acesso em 2020 jun 18]. Disponível em: https://bit.ly/3fZB5YK.

64. Cajado AFR. O voto na colônia. Brasília: Tribunal Superior Eleitoral, 2013 [internet]. [acesso em 2020 jun 22]. Disponível em: https://bit.ly/2BJ19Lq.

65. Glied S, Levy H. The Potential Effects of Coronavirus on National Health Expenditures. JAMA. 2020; 323(20):2001-2002.

Recebido em 29/06/2020

Aprovado em 02/11/2020

Conflito de interesses: inexistente

Suporte financeiro: não houve 